\title{
Research on the Network Technology Security
}

\author{
Wang Rong \\ Jiangxi College Of Foreign Studies
}

\begin{abstract}
As the rapid development of science and technology in recent years, computer network technology also shows a tendency of rapid development and gradually becomes widespread in people's life. Computer technology has been widely used in people's production and life. The effects of computers can be seen in all aspects of life. How to reform and develop enterprise informatization is a concern. The effects of the application of computer network technology to enterprises is huge. If enterprises want to gain a foothold in the international society, they will have to consider the influence of computer network technology. This paper mainly analyzes the computer network technology and enterprise information characteristics, then understands the survival status and the faced problems in the future of enterprises, discusses several kinds of technologies to improve the network security and emphatically discusses the concept and classification of the firewall technology.
\end{abstract}

KeyWords-Network technology; Network security; Firewall; Computer network technology

\section{INTRODUCTION}

The research and development of computer network greatly influenced the science, economy and society of the world. Information related fields are rapidly fusion. The island phenomenon of the acquisition, transmission, storage and processing of information is gradually disappearing with the development of computer network and multimedia technology. Telecommunication network, television network and computer network which develop on their own will converge. A new information industry is in a strong momentum of rapid rise. To use the Internet or other public network to process the communication inside enterprises or between enterprises and to provide secure like private network, it is necessary to establish a safe virtual private network to meet the needs of the global business environment.
The main operation mode of computer network is to connect and use computers at different geographical location and in different environment, in which there are all kinds of equipment. As a new product, computer is an important sign of the time and has the vital significance in the development of the time. The development of any things has the process from low level to high level, which is the same for the computer. It is based on the predecessors' efforts that makes we can now share network resources in society. There is a saying which is popular that if you have problems, you can search for answers on Baidu. People can search for information they need on Baidu. The computer network system can realize the resource sharing of worldwide, which brings great convenience for the life of people. There are many kinds of computer network. According to different reference objects, computers can be divided into different categories. According to the using range, computers can be divided into special mode and common mode; According to cover forms, computers can be divided into LAN, WAN, metropolitan area network and the Internet; According to the topological structure, computers can be divided into centralized, distributed and decentralized ways.

This paper discusses how to use the Internet or other public network to process the communication inside enterprises or between enterprises, establishes a secure private network and analyzes computer network technology.

\section{THE SECURITY PROBLEMS OF COMPUTER NETWORK}

\section{A. The problem of computer network system}

Computer network gets so popular today, but in this process, there are still many inevitable problems. Some uninvited guests usually use some weaknesses of systems to attack computer systems, in order to achieve the goal of their own. And the computer has very limited protection to itself. The main problems existing in general are a lot of 
security problems brought by the unreasonable design, which also affects the stability of the system.

\section{B. Computer virus}

During the process of using computer in people's daily life, the most things that make people be upset is the network breaks off suddenly and computer becomes black screen, blue screen, and even crash, which is called computer virus. Because the virus itself has strong destructive and sudden, so once it is triggered, computer will be damaged seriously and cannot be in normal use. There are numerous events like this, which are needed to be paid attention to.

\section{NETWORK SECURITY FEATURES}

In today's information society, computers are no longer strange for people. They have become an important part of people's life. Why computers can be so popular and what kind of charm of computer which can make people use them so widely, it is needed to talk from the characteristics of them. The characteristics of computer network mainly include the following aspects: firstly, saving money. People usually use computers with a lot of different performance, so for different computer and different performance, there will be different price. So to save money is also derived from different trial functions and usage patterns. Secondly, the scalability. People can increase the performance of the network by increasing the number of processors according to their own needs, which can effectively avoid the problems when work load is too large.

Network security has the characteristics as follows:

(1) The network security is from the diversification of security policy and technology.

(2) Network security mechanism and technology change at the same time.

(3) The network is used in the society and the means to access the network will be more and more. People adopted many security technologies to improve the security of the network, in which the most representative are: data encryption, fault-tolerant technology, port protection and principal part validation, and Firewall technology. Among them, the firewall technology is a network security technology which is put forward and promoted in recent years.

\section{THE CONCEPT AND ITS CLASSIFICATION OF FIREWALL}

For the problems of computers, people have carried on exploration and also put forward some solutions at the same time, including firewall technology. Now a lot of computers install the firewall, which can isolate the virus and the computer. It is the equivalent of a layer of protective film, which can realize the computer protection, avoid some virus, which is a kind of isolation control technology. Firewall is now a widely used technology, and is also a technological innovation with great benefits which is emerge in computer network systems.

Network firewall is a software which is located between the computer and the network it is connected. All network communication which flows through the computer will be through firewall. Firewall scans the network communication which flows through it, which can filter out some of the attacks, lest they be executed on the target computer. Firewall can also close ports which are not in use. It also can ban the communication output of a specific port and to block Trojans. Finally, firewall can ban the access of special websites, so as to prevent all communication from unknown intruders.

Firewall can inspect the data packets which are transferred between two or more networks, such as link ways, according to certain security policy to determine whether the communication between networks is allowed and to monitor the network running status. The firewall on the Internet is shown as Fig .1. 


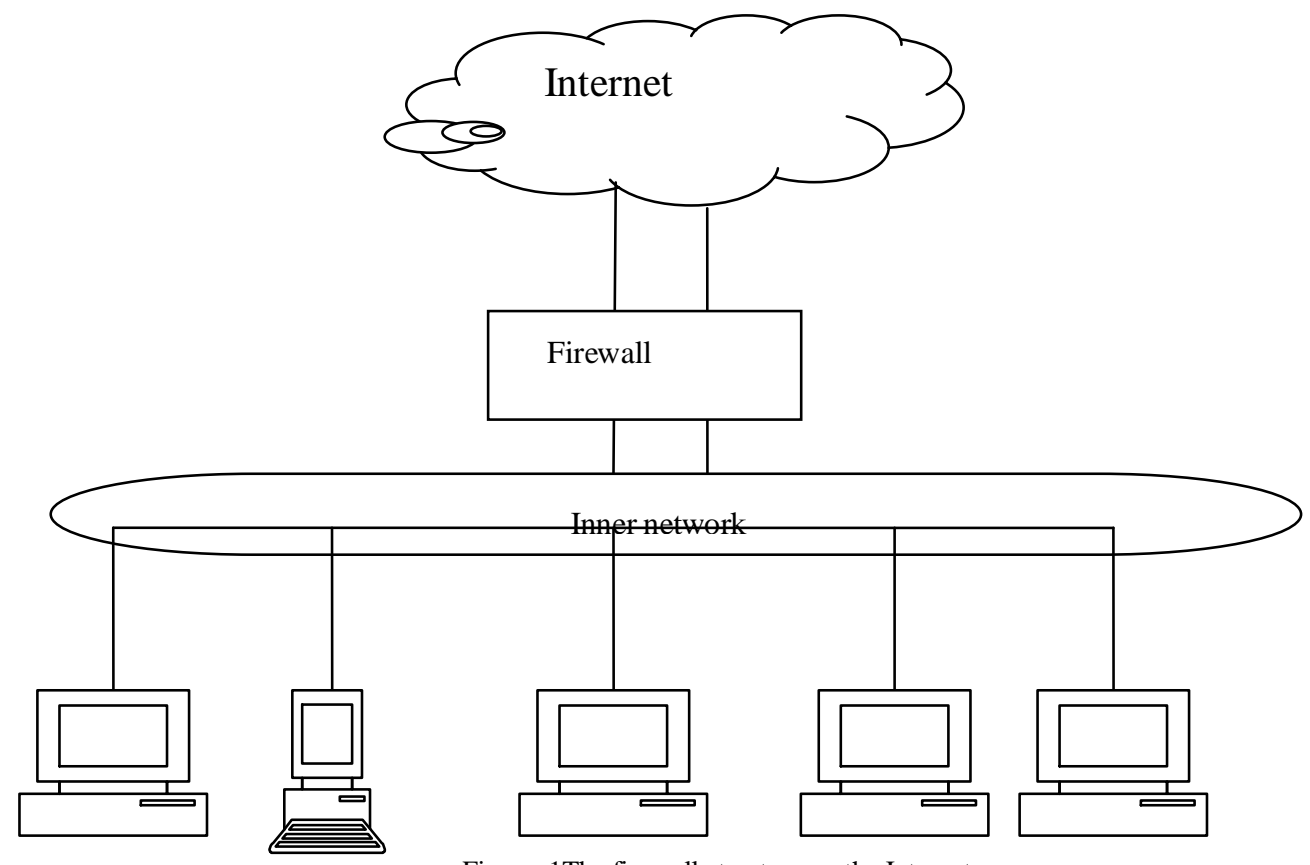

Figure .1The firewall structure on the Internet

\section{CONCLUSION}

With the development of computer network and the improving of the level of enterprise information, it has gradually become the trend of the time that enterprises use computer information technology. In the face of the situation that computer technology is gradually into the production and life, people just need to constantly enrich themselves and constantly improve the management level of the computer network system, and make enterprises have a all-round development on the premise of providing power for enterprises. The application of computer network technology in the enterprise information also requires people to learn computer network technology and to pay great attention to the computer network security. Only constantly enrich themselves and enrich the computer network system can make people produce correspondence between computer networks and enterprises. This paper mainly tells the application of computer network technology and network security. According to this paper, the importance of network security to daily life and the mutuality between the network security and network technology can be learned. Finally, this paper introduces the importance of the firewall to network, as well as the classification and structure of firewall, and introduces how to guard against network threats.

\section{REFERENCES}

[1] Carman, D. W., Kruus, P. S., Matt, B. J., Carman, D. W., \& Kruus, P. S. (2000). Constraints and approaches for distributed sensor network security. Darpa Project Report.

[2] Singh, Prashant, P. K. Sharma, and T. K. Aggarwal. "Cryptography And Network Security Principles And Practices." International Journal of Engineering \& Computer Science volume 11.7(2005):655-660.

[3] Li T. An immunity based network security risk estimation[J]. Science in China, 2005, 48(5):557-578.

[4] Stallings, W., and W. Stallings. "Network security essentials: applications and standars." Upper Saddle River N J (2003).

[5] Heberlein, L. T., Dias, G. V., Levitt, K. N., Mukherjee, B., Wood, J., \& Wolber, D. (1990). A Network Security Monitor. 2013 IEEE Symposium on Security and Privacy (pp.296-296). IEEE Computer Society.

[6] Guttman, Joshua D., and A. L. Herzog. "Rigorous automated network security management.." International Journal of Information Security 4.1-2(2005):29-48.

[7] Roy, S., Ellis, C., Shiva, S., Dasgupta, D., Shandilya, V., \& Wu, Q. (2010). A Survey of Game Theory as Applied to Network Security. hicss (pp.1-10). IEEE Computer Society.

[8] Stallings, W., and W. Stallings. "Network security essentials: applications and standars." Upper Saddle River N J (2003).

[9] Heberlein L T, Dias G V, Levitt K N, et al. A Network Security Monitor[C]// 2013 IEEE Symposium on Security and Privacy. IEEE Computer Society, 1990:296-296.

[10] Singh P, Sharma P K, Aggarwal T K. Cryptography And Network Security Principles And Practices[J]. International Journal of Engineering \& Computer Science, 2005, volume 11(7):655-660.

[11] Li, Tao. "An immunity based network security risk estimation." Science in China 48.5(2005):557-578.

[12] Alpcan, Tansu, and T. Baar. "Network Security - A Decision and Game-Theoretic Approach." Journal.publications.chestnet.org (2011). 